\title{
Reciprocal Value Co-Creation in Care Services: A Case Study of L'Arche Kananoie
}

\author{
Tetsuya Muramoto*, Michitaka Kosaka ${ }^{\dagger}$
}

\begin{abstract}
In this research, we discuss service value co-creation in care services, especially those for the disabled. A "Reciprocal Value Co-Creation Model" in which both service users and care workers in service providers create value and share in that value together is proposed. Furthermore, using a case study from L'Arche Kananoie, a care service provider for the intellectually-disabled, we will show the model in practice and show how this organization's service users and care workers collaboratively create value such as "a place to belong," "human growth," and "a connection to society."
\end{abstract}

Keywords: care services, care worker, service value co-creation, well-being.

\section{Introduction}

The chronic manpower shortages of care workers in care services providing care to the elderly and the disabled is a serious issue in Japan. One of the big contributing factors for this shortage is the small reward in proportion to the hard work. On the other hand, there are care workers who find value in their work besides monetary value, such as the meaningfulness of their work, etc. and they have continued to be care workers for a long time. By enhancing the non-monetary value of working as a care worker, we will be able to attract more workers into the welfare industry, alleviate manpower shortage, and eventually lead to the improvement of care services.

Mayeroff [1] describes care services as services which support users to pursue "well-being of their lives" through establishing long-term wholehearted relationships of human to human. $\mathrm{He}$ also mentions that through the experiences of helping others, care workers also can live their lives well. We believe that this reciprocity is the key to understand the value co-creation system of care services. Conventional service researches mainly discuss value for customers or users. However, when we study care services, value for care workers, which is derived from the act of caring, should be taken into consideration as an important element of service system. In view of both value for care workers and users, we can better understand care service value creation system.

\footnotetext{
* Japan Advanced Institution of Science and Technology

$\dagger$ Japan Advanced Institution of Science and Technology
} 
In this research, we focus on value for care workers and try to understand what are they and what factors promote the value co-creation. Firstly, we examine the precedence research regarding non-monetary value and value for care-workers. Then, we introduce Reciprocal Value Co-creation model. Thirdly, we examine a case of care service provider to see how the reciprocal value co-creation happen in the real setting. Finally, we discuss promotion factors of reciprocal value co-creation.

\section{Value co-creation in social service}

In this chapter, we will first examine precedence researches of value co-creation and propose a "Reciprocal Value Co-Creation Model", where both service users and providers each create their own value.

\subsection{Non-monetary value}

Toya classifies co-created vales in three categories as Monetary Value (MV), Knowledge Value $(\mathrm{KV})$, and Emotional value (EV). She also emphasizes on the importance of non-monetary value such as $\mathrm{KV}$ and $\mathrm{EV}$ [2]. KV is knowledge accumulated in both service providers and users and make them possible to increase vale. EV is emotions generated through the interaction of users and workers such as excitement, joy and trust. As Mayeroff suggests, non-monetary value created in care services are like well-being or trust, we focus on EV in this research.

\subsection{Value for care workers}

(1) Employee satisfaction: One non-monetary value for service workers prevalent in conventional discussions is the satisfaction of the employee. Employee satisfaction is often talked about in the context of internal marketing or service-profit chains. The service-profit chain states that employee satisfaction leads to the improvement of the service value to customers through increasing employee loyalty and motivation [3]. Employee satisfaction can be considered as one of the elements to improve the quality of service provided to the service users. In other words, employee satisfaction is a method of creating value for service users, whereas the idea of it creating value for employees themselves is weak.

(2) Well-being: According to Baba's research [4], value of "the act of taking care of someone" is to gain something that is "only brought about through a relationship with that person, something that is necessary for well-being." Furthermore, "The act of taking care of someone is a relationship that is established through human interaction. It can be considered as a reciprocal relationship between the caregiver and the care receiver. It is not a one-sided act from the caregiver, there is something to be given from the care receiver to the caregiver, it has a reciprocal framework," wrote Baba, suggesting a reciprocal value co-creation relationship.

\subsection{A reciprocal value co-creation model}


Based on the above, we think that it is necessary to examine the value gained by workers in care services and to come up with a model for it. In order to more comprehensively understand value creation of care services, Figure 1 shows the "Reciprocal Value Co-Creation Model" that includes both the values of users and providers. In this model, we introduced the objectives and satisfaction of the workers in providing services as a constituent element of the service. This will show the structure of both the service users and providers gaining satisfaction by achieving their respective objectives through reciprocally created values. Furthermore, as an important element for the establishment of a reciprocal value co-creation relationship, we introduced shared values and service-ba and indicated how these elements relate to value co-creation. Each constituent element is explained as below.

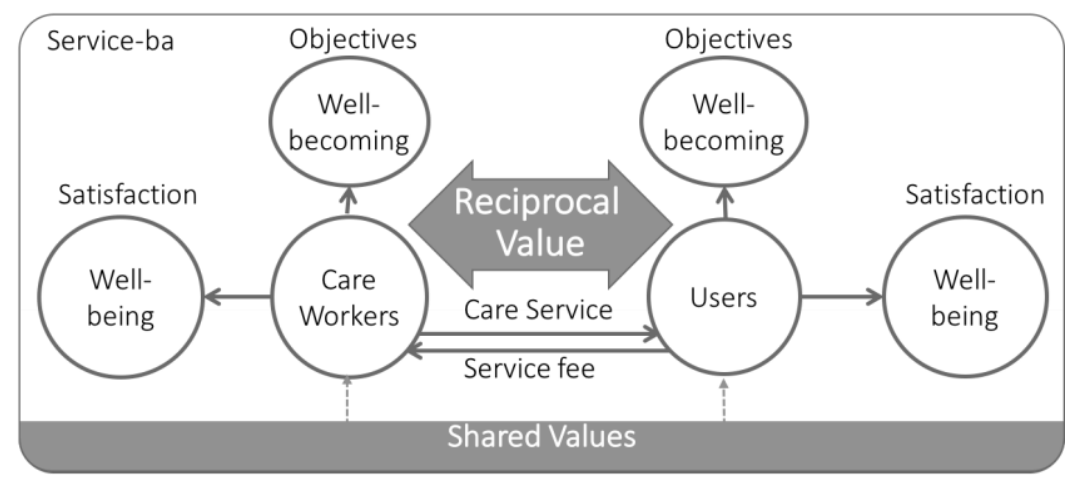

Figure 1: Reciprocal Value Co-Creation Model

(1) Objectives: The objective of users is to receive the services and the objectives of workers is to provide these services. The objective of users has been mentioned above. The Reciprocal Value Co-Creation Model also takes into consideration the values for workers. The objective of workers can be thought of as aspiring for well-being (well-becoming) as mentioned in Baba's research. In other words, it can be said that they share the same goal with service users.

(2) Satisfaction: Similarly, the satisfaction of the workers is also taken into consideration in this model. The satisfaction of workers is also the same as that of the users, which is "well-being."

(3) Reciprocal Value: Value co-created by users and workers, and through this value, both users and workers are able to satisfy their respective goals.

(4) Service-ba: A physical and social place where service is provided.

(5) Shared values: Values shared among workers, users and other stakeholders such as member of the board. Some are stated clearly, like a corporate philosophy, and some exist implicitly like corporate culture.

\section{Case analysis}

In this section, L'Arche Kananoie, a social welfare corporation for intellectually-disabled is investigated as an example of successful reciprocal value co-creation. 


\subsection{Outline of L'Arche Kananoie}

The L'Arche Kananoie Social Welfare Corporation (hereinafter referred to as Kananoie) is the only community affiliated with L'Arche International in Japan. L'Arche International is a NGO which promotes to develop communities where people with and without intellectual disabilities are living together. L'Arche is operating 147 communities in 35 countries on world-wide [5].

Kananoie was started when the intellectually-disabled persons and facility staff living at a largescale facility felt many problems living at the large facility and moved into a normal home in Shizuoka City in 1978 in order to live a more humanly life [6]. Later, the founder of Kananoie, Yoshihiko Sato, became aware of L'Arche. The activities of L'Arche resonated with him, and Kananoie became a member of L'Arche International in 1991. Currently, as a social welfare business, Kananoie operates group homes (communal living support) and multi-functional welfare service for the disabled. There are about twenty-something users and between 10-20 workers at Kananoie. At Kananoie, service users are referred to as "Nakamanohito (Friends)" and workers are referred to as "Assistants."

\subsection{Value recognized in the L'Arche community}

After a preliminary investigation, the values provided by Kananoie to its Nakamanohito and the Assistants can generally be summarized into the following five values.

(1) Care services for the disabled: The care provided for daily life, employment support, assistance in communal living, etc. to disabled persons offered by social welfare corporation. Nakamanohito pay the compensation mainly for these services. These are value that is provided onesidedly by the Assistants to Nakamanohito.

(2) Job opportunity: To the Assistants, Kananoie provides job opportunities as ways to earn income. To Nakamanohito, job assistance services offer opportunities for production activities (producing soaps, farming, miscellaneous jobs, etc). Users receive wages for their work.

(3) A place to belong: A place where one feels accepted. Where a person can be who he or she is and can express themselves. A place for an active life. A place to belong is created together by the Assistants and Nakamanohito. Kananoie is able to provide a place where they can both acknowledge each other's presences.

(4) Human growth: The Assistants are exposed to the qualities of the Nakamanohito, like "ability to accept others," "ability to become friends," and "ability to accept weaknesses." Through this, they learn to reconsider their way of lives and shared values, as well as move forward in the pursuit of human growth and self-actualization. Through their experience at Kananoie, the Assistants also grow personally. Furthermore, they reinforce their own growth and self-actualization through providing care services to Nakamanohito. This human growth and self-actualization is achieved via the interactions between Nakamanohito and the Assistants. In other words, they are co-created. 
(5) A connection to society: Supporting intellectually disabled persons to get involved in society. The Assistants are also able to get involved in society by participating in various events with Nakamanohito. The qualities of Nakamanohito mentioned above facilitate the forming of relationships between people when trying to get involved in the society. In this way, we can say that "A connection to society" is reciprocal and jointly created.

\subsection{Quantitative analysis}

A questionnaire survey was conducted in order to understand in a quantitative manner how the Assistants actually think about these values. The survey was done by calculating the weight of each value using the AHP (Analytic Hierarchy Process) method. Here, we set out to verify the levels of importance accorded to each of the five values, both by the users and the workers. Figure 2 shows the AHP model that is used to prepare an AHP questionnaire.

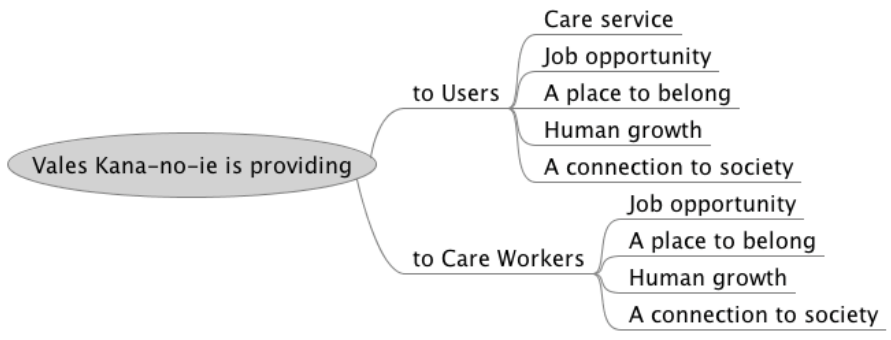

Figure 2. AHP model

Two AHP questionnaire sheets were created and responses from 15 Assistants were collected. The questionnaire requires the respondent to choose one out of two values which the respondent thinks is more important than the other. Respondents were asked this question in every possible value pair. Figure 3 shows an AHP questionnaire asking about value for users. Figure 4 shows an AHP questionnaire asking about value for care workers. Value "Care services" is omitted in this questionnaire because care service is only for users.

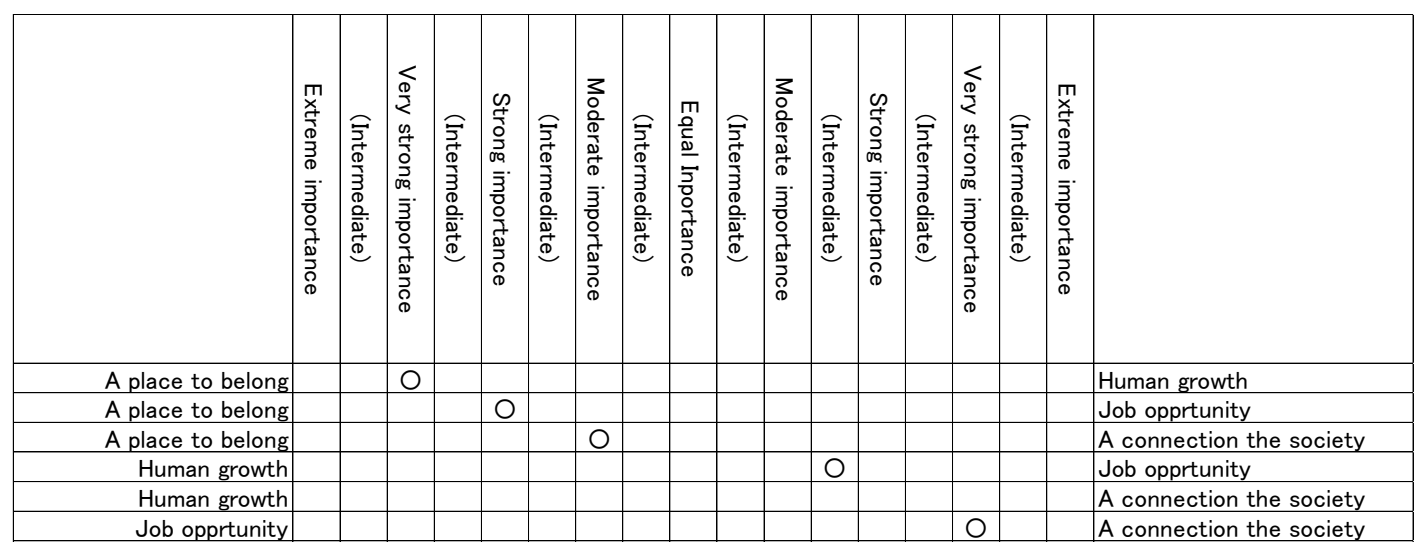

Figure 3. AHP questionnaire asking about value for users 


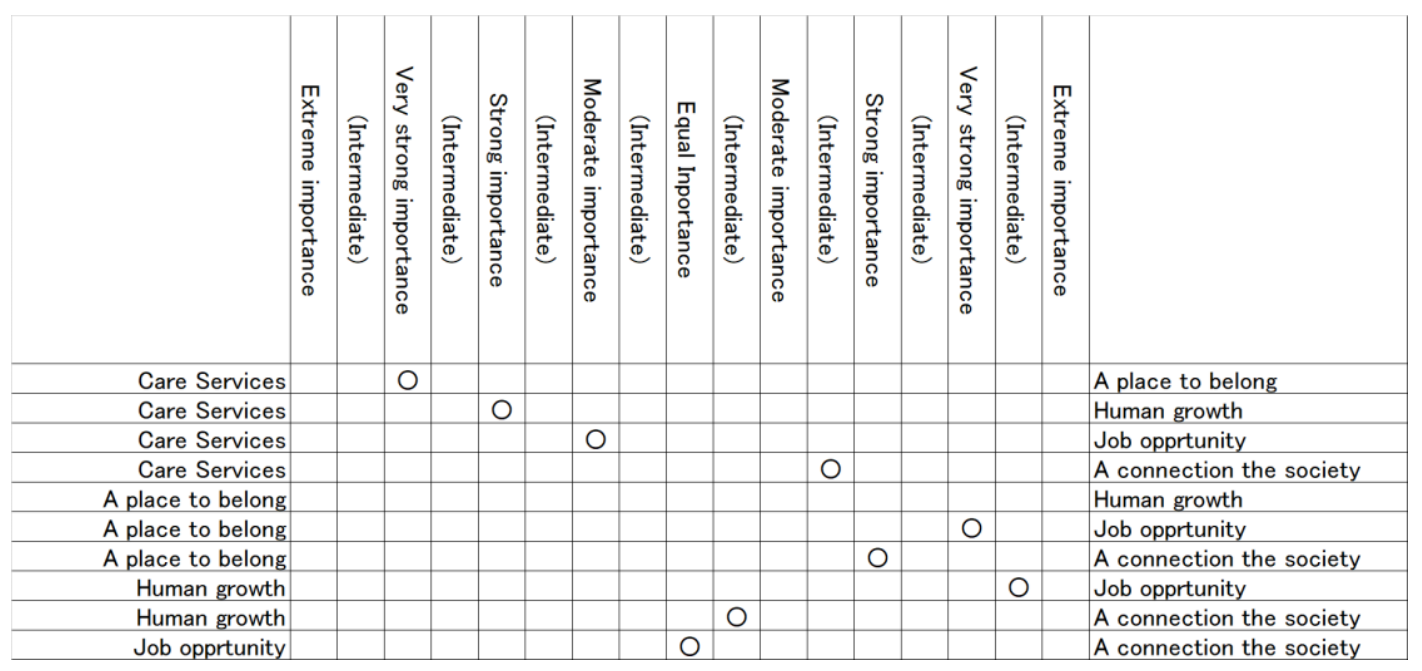

Figure 4. AHP questionnaire asking about value for care workers

Using the AHP method, the weight of each value, in other words the level of importance accorded, of each questionnaire response was calculated.

Then, the average values across all responses were calculated. The average weight calculated using all responses is considered the levels of importance of each value as perceived by the Kananoie Assistants. Figure 5 shows the importance of each value to the care workers (Assistants) and to the users (Nakamanohito).

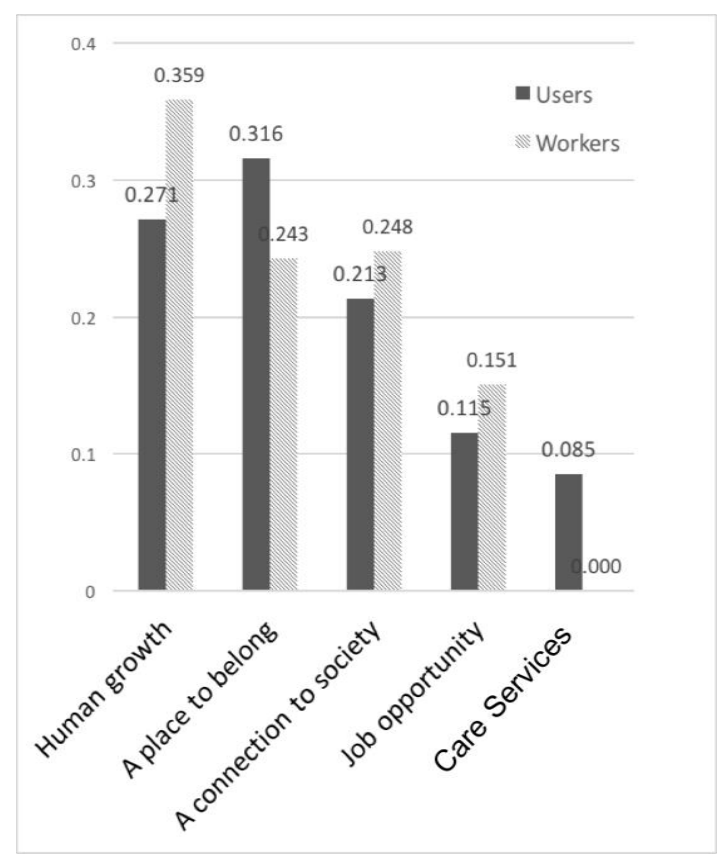

Figure 5. Importance weight of values 
For both users and workers, "Human growth," "A connection to society," and "A place to belong" are the three values of highest importance, therefore we can see that both users and workers found the same values as important. In addition, these three values are those evaluated as reciprocal cocreated values in the previous section.

On the other hand, "Care Services" and its compensation, "Job Opportunities" were regarded as having relatively low importance. From this point, we can conclude that at Kananoie, the wellbeing of users and workers had higher importance than care services as a job.

\subsection{Qualitative analysis}

Next, we investigated specifically how these values are jointly created at Kananoie through interviews with the Assistants, literature survey and participant observation.

\subsubsection{Interviews}

A semi-structured interview was conducted with three workers to ask questions on three aspects: value for users, value for workers, and how Kananoie differs from other care service providers. Table 1 shows the interview questions and followings are remarks.

Table 1: Interview Ouestions

\section{No. Question}

1 What value do you think you are providing to the Nakamanohito of Kananoie?

2 What value do you think Nakamanohito can gain with Kananoie being affiliated with L'Arche?

3 What have you gained from working and living at Kananoie?

4 What value do you think Assistants can gain with Kananoie being affiliated with L'Arche?

5 What do you think are the differences between Kananoie and other care service provid-

Value for users (a place to belong): "When people visit us, they say that people here at Kananoie are always cheerful. I guess it's because we are able to say what we want to say, and everybody at Kananoie tries to acknowledge our Nakamanohito. I think there's something about everyone being able to freely express what they're thinking."

Value for workers (growing as a human): "Once, a Nakamanohito had collapsed from epileptic seizures and ended up wetting his pants. Since his pants were dirty, I changed him out of it. Once he regained consciousness, realizing what I had done, he said 'thank you'. That came as a huge shock to me; if I was in the same situation, having someone change me out of my dirty clothes, I would feel ashamed and apologetic. I wouldn't have been able to meekly say thank you to the 
person who helped me. But after seeing that, I came to humbly accept myself as someone with seizures, with no choice but to have someone help me. I can say 'thank you' to them. I let my shortcomings and helplessness be exposed. I think having people recognize that you have shortcomings and deficiencies is a form of growth. We don't change, but we can come to understand ourselves."

Value for workers (A place to belong): "Because there is no competitiveness amongst Nakamanohito, for them, happiness isn't work success, but who they become friends with. What I like about being with them is, even though I'm not successful, they still say they like me when I am just being myself. Actually, we are also seeking that, but Nakamanohito tell it to us straight, and in that way, I feel warm and happy when I'm with them. They teach me that actually that's enough.”

Through the interviews, we are able to reconfirm that Assistants feel the value of "Personal Development" and "A place to belong".

\subsubsection{Literature Survey}

Existing literature about L'Arche was surveyed to confirm the reciprocal value co-creation relationship. One of literature is written by Vanier, the founder of L'Arche. He addresses the personal growth of the Assistants and the value of Nakamanohito in his statement below [7]:

"I am touched by the stories of young men and women who have been in L'Arche for three or four years living in a house with people with intellectual disabilities. So many affirm that they have been transformed by the people they live with, by their simplicity, their trust....In spite of the difficulties, I can truly bear witness to the power of love that attracts many assistants and anchors them in L'Arche.... There is something that reveals to them the fundamental beauty of their humanity."

\subsubsection{Participant Observation}

One of the authors is a member of the Board of Kananoie for over 10 years. His experiences and observations make it clear how a sense of values that stresses reciprocal value co-creation is shared and in what form value co-creation is promoted. Followings are an example of mechanisms that facilitate sharing sense of values within Kananoie:

A "Sharing meeting" is conducted daily. In the meeting, Nakamanohito and Assitants can share what they are thinking about or what is troubling them. The sharing session isn't just a meeting conducted by the Assistants. It is a chance for the Assistants and Nakamanohito to share thoughts, and by thinking together, discover solutions. It is also common for the Assistants to be exposed to the gifts of Nakamanohito through this sharing.

\section{Discussion}


We have seen above the actuality of the co-creation of reciprocal values at Kananoie. We also found that reciprocal value co-created in Kananoie are "A place to belong," "Human growth," and "A connection to society." In this section, we will discuss factors that promote reciprocal value co-creation based on Figure 6, the summary of the case study findings with reciprocal value co-creation model.

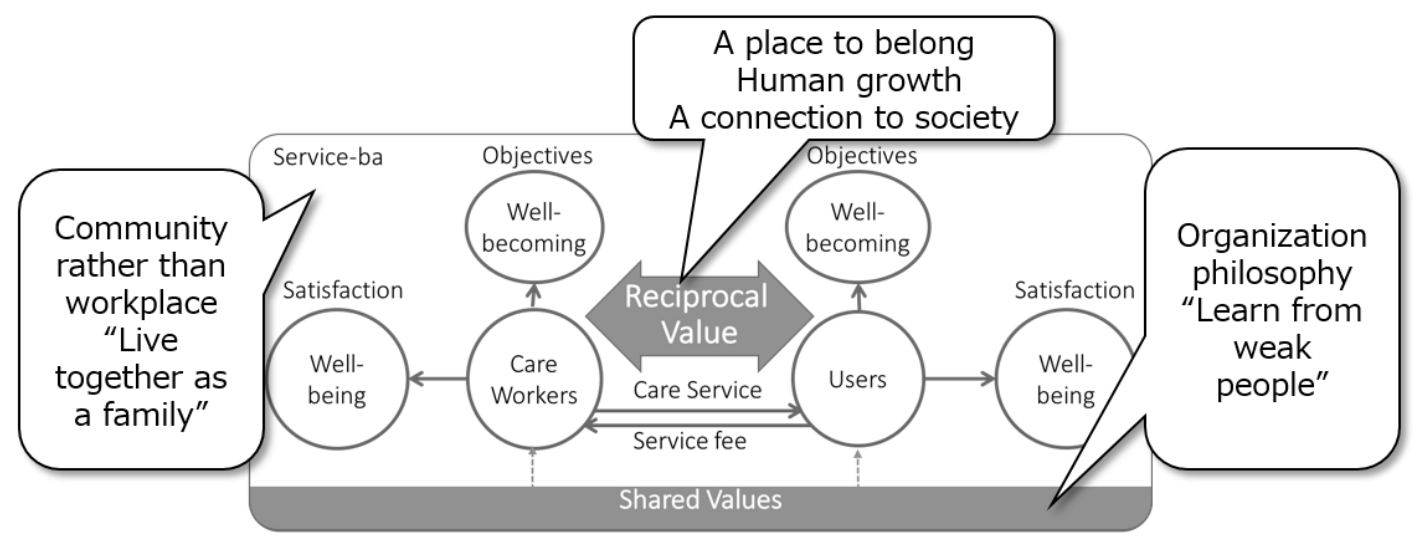

Figure 6. Summary of the case study findings

According to the McKinsey's 7S Framework [8], shared values impact all aspects in the organi-zation and play a central role in defining the direction of the organization. In our model, shared values are part of the service-ba. Shared values define the nature of the service-ba, and at the same time, through the service-ba, shared values impact the ways of thinking and behavior of the users and care workers.

The shared values held by the organization play a very important role in deciding whether a re-ciprocal value co-creation relationship is established or not. For example, if a service provider prefers "fuss-free service users", they would avoid forming deep relationships with users as much as possible. In this situation, a reciprocal value co-creation relationship will unlikely be estab-lished. In case of Kananoie, as found in interviews, when an Assistant encounter a situation in which a Nakamanohito is incontinent, he doesn't think, "It's more work for me." In order for them to realize the previously undeveloped greatness within themselves, it's important for them to share the values such as "learning from weak people." Furthermore, organization culture and training, along with daily events such as sharing meeting, are important for helping Assistants take this awareness and these skills to heart.

We believe that design of service-ba is also an important factor for promoting reciprocal value co-creation. Especially, how the users and workers perceive the service-ba is important. Whether the worker perceives it as a workplace or a community to spend time with friends, or whether the user perceives it as a place to receive services or a family to live together, how the constituent members perceive the service-ba affects the establishment of a reciprocal co-creation relationship. Through interviews and literature study, We can see that Kananoie has created a family-like ser-vice-ba successfully and has made Assistants feel that Kananoie is a place that they belong to. 


\section{Conclusion}

Based on the above quantitative and qualitative research, we could confirm that reciprocal value co-creation occurs at Kananoie. The care workers and users at Kananoie live like a family and while interacting with one another wholeheartedly, they are able to realize the well-being of one another. We were also able to confirm that the three specific values in the aforementioned wellbeing are "A place to belong," "Human growth," and "A connection to society." In addition, we also found out that the philosophies of L'Arche, i.e. "Learning from weak people" and "Living together like a family" play an important role in establishing a reciprocal value co-creation relationship, and it is important to incorporate these philosophies with the service-ba and to make sure that the all stakeholders are always aware of them.

We believe that in order to establish the co-creation of reciprocal values in a service provider, it is important for that provider to choose a value system that incorporates elements of reciprocity, then align every aspects of organization such as management system, organization structure, and decision making process, with that value system. Those aspects are difficult to change in a short period of time. It is necessary for service providers to use every opportunity to construct the value system persistently over time. By carrying out service providers' operations in such way, this leads to the improvement of employee satisfaction as well as the increase in the quality of services provided to users.

\section{Acknowledgment}

We would like to express our gratitude to Kananoie for their cooperation in our research.

\section{References}

[1] M. Mayeroff, “On Caring”. William Morrow Paperbacks (Reissued), 1990.

[2] K. Toya, "A Study of Structure of Service Value Co-Creation", Marketing Journal, vol. 33.3, 2014, pp. 32-45.

[3] J. L. Heskett, et al, "Putting the Service-Profit Chain to Work", Harvard Business Review, 2008, July-August 2008 issue.

[4] J. Baba, "What is "Care" or "Caring"?", Human Welfare Review, vol. 3,2000, pp.59-78.

[5] L'Arche International, “Our history”, JUN. 201; www.larche.org/discover/ourhistory/.

[6] L’Arche Kananoie, “Our history”, JUN. 2016; www7.plala.or.jp/kananoie/whatislarche.htm.

[7] J. Vanier, Letter to My Brothers and Sisters in L'Arche, 1996

[8] R.H. Waterman et al, "Structure is not organization", Business Horizon, vol. 23, No. 3, 1980, p.14-26. 